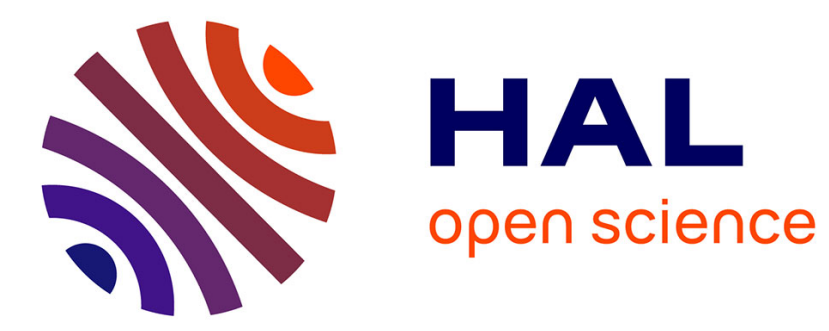

\title{
Experimental Investigations on Fluidic Control Over an Airfoil
}

Sébastien Bourgois, Jean Tensi, Emmanuel Sommier, Julien Favier

\section{To cite this version:}

Sébastien Bourgois, Jean Tensi, Emmanuel Sommier, Julien Favier. Experimental Investigations on Fluidic Control Over an Airfoil. Journal of Flow Visualization and Image Processing, 2006, 13 (3), pp.265-286. 10.1615/JFlowVisImageProc.v13.i3.40 . hal-01073973

\section{HAL Id: hal-01073973 https://hal.science/hal-01073973}

Submitted on 11 Oct 2014

HAL is a multi-disciplinary open access archive for the deposit and dissemination of scientific research documents, whether they are published or not. The documents may come from teaching and research institutions in France or abroad, or from public or private research centers.
L'archive ouverte pluridisciplinaire HAL, est destinée au dépôt et à la diffusion de documents scientifiques de niveau recherche, publiés ou non, émanant des établissements d'enseignement et de recherche français ou étrangers, des laboratoires publics ou privés. 


\title{
Experimental Investigations on Fluidic Control Over an Airfoil
}

\author{
Bourgois, S. ${ }^{1}$, Tensi, J. ${ }^{1}$, Sommier E. ${ }^{1}$,Favier, J. ${ }^{2}$
}

1. Laboratoire d'Etudes Aérodynamiques, Ecole Nationale Supérieure de Mécanique et d'Aérotechnique, Téléport 2, 1 Avenue Clément Ader B. P. 40 109, 86961 Futuroscope Chasseneuil CEDEX, France.

2. Institut de Mécanique des Fluides de Toulouse, Allée du Professeur Camille Soula, 31400 Toulouse, France.

e-mail: sebastien.bourgois@lea.ensma.fr

\begin{abstract}
This study presents the development of two fluidic actuators - namely, microjets and tangential blowing actuator (TBA), designed for flow separation control. The developed actuators are compact enough to fit inside an ONERA D profiled wing with a chord of $0.35 \mathrm{~m}$. Test bench experiments showed that the microjets (resp. TBA) were able to produce exit velocities up to $330 \mathrm{~m} / \mathrm{s}$ (resp. $60 \mathrm{~m} / \mathrm{s}$ ). These actuators were placed in the model and were tested in wind tunnels for various blowing rates. The investigations included the use of force balance measurements, on-surface flow visualization with pigmented oil, off-surface flow visualizations with smoke, surface pressure distribution measurements, and Particle Image Velocimetry (PIV). Most of the tests were performed at freestream velocities between $20 \mathrm{~m} / \mathrm{s}$ (for PIV) and $40 \mathrm{~m} / \mathrm{s}$, corresponding to Reynolds numbers in the range $0.47 \times 10^{6}-0.93 \times 10^{6}$. The angle of attack varied from -2 to 20 degrees. Experiments were conducted using the naturally occurring laminar boundary layer as well as for a turbulent boundary layer. In such a case, rough strips were used in the vicinity of the leading-edge. The present tests show the efficiency of these devices to delay separation and improve aerodynamic performances of the wing: for example, a maximum of $30 \%$ gain in $C_{L}$ has been reached using the microjets. Both actuators tend to increase the lift coefficient $C_{L}$ after stall and areas of separated flow have been eliminated by applying control, as suggested by flow visualizations and PIV velocity fields.
\end{abstract}




\section{Introduction}

In most aerodynamic applications, whether in internal flows such as engine inlets, diffusers, or external flows, such as flow over wings and other control surfaces, the separation of a boundary layer is highly undesirable due to its adverse effect on performances. Consequently, means of preventing boundary layer separation has received a great deal of attention since the beginning of the twentieth century. Various methods have been employed in the past. Mechanical control techniques were the first to be developed because of their simplicity (slats, flaps, mechanical vortex generator...) $[1,2]$. Acoustic methods have also been experimented, mainly using loudspeakers. The few fluidbased techniques that were examined in the past mainly relied on boundary layer suction to remove the low momentum boundary layer fluid, or direct tangential blowing - to energize it. However, the high mass flow/power requirement for these methods has, to date, made them impractical for most applications. More recently, the development of Micro Electro Mechanical Systems (MEMS) has driven to an important use of pulsed and synthetic blowing micro systems [3, 4], piezoresistive actuators [5] and other devices, which provide an energy input to the flow being manipulated.

In this article, fluidic methods were investigated on the wall of an ONERA D airfoil model by means of discrete injectors in order to delay the separation on the upper side of the wing. Two main blowing techniques were successfully tested: the first one, normally to the chord, using small micro jets [6] regularly drilled along a line parallel to the leading edge; the second one, tangentially applied [7] to the surface through a thin slot. The aerodynamic forces (lift and drag) and the mean wall pressure distribution at mid span were measured. Other investigations include: wall observations (oil film method), visualizations by laser tomoscopy in the vicinity of the actuators (at low Reynolds numbers), and Particle Image Velocimetry (PIV) measurements in the region of separation. 


\section{Experimental Set Up}

\subsection{Wind tunnel facilities}

The experiments were conducted in the «Béton» wind tunnel (Figure 1) located at the Laboratoire d'Etudes Aérodynamiques (LEA). The tunnel is of closed-loop type with a 7:1 contraction ratio. The test section is $2.4 \mathrm{~m}$ wide by $2.6 \mathrm{~m}$ high by $6 \mathrm{~m}$ long. The turbulence-reduction devices upstream of the contraction consist of a honeycomb followed by two filters. An axial fan powered by a $250 \mathrm{~kW}$ motor is used to drive the tunnel. Speeds of $60 \mathrm{~m} / \mathrm{s}$ are reachable in the test section with measured turbulence intensities $\sqrt{\overline{u^{2}}} / U_{\infty}$ (u longitudinal component of the velocity) of approximately $0.2 \%$. Plexiglas windows are disposed in the test-section ceiling for wall visualizations. In addition, aerodynamic forces are measured by a force balance installed below the test-section floor.

PIV experiments were performed at the IMFT subsonic wind tunnel "S1". The circular test section ( $2 \mathrm{~m}$ of diameter) is opened allowing large access for optical installations. The velocities tested during the study were from $15 \mathrm{~m} / \mathrm{s}$ to $25 \mathrm{~m} / \mathrm{s}$ and the rate of turbulence was $0.5 \%$. The loads measurements were performed using an aerodynamic balance located under the wind tunnel test section.

\subsection{Experimental PIV set up}

Particle Image Velocimetry (PIV) was used to measure instantaneous two-dimensional velocity in the streamwise plane normal to the wall at midspan. The flow field was seeded using particles of DEHS, whose typical size is $1 \mu \mathrm{m}$. The observation of the flow field was made using a 14 bits PCO 2000 CCD camera which was fixed on a rotary table in order to follow the variation of angle of attack of the airfoil. The camera (2048 x 2048 pixels) was equipped with a $85 \mathrm{~mm}$ objective lens at a diaphragm aperture of 8 . 
The laser used was a double-pulsed Nd-YAG laser Quantel $(2 \times 200 \mathrm{~mJ})$ and the time interval between two flashes was set to $20 \mu$ s or $15 \mu$ s depending of the velocity upstream. The system, both camera and laser, was set to operate at a frequency of $10 \mathrm{~Hz}$. The timing between the two flashes and the synchronisation with the camera was controlled with a PC. The measurements were carried out at midspan in order to observe the flow field all along the chord. Two areas were investigated, one near the leading edge and the other one further downstream, near the trailing edge. For each configuration (angle of attack and Reynolds number) and each area of measurement, 1000 pairs of images were stored, having a spatial resolution of 2048 x2048 pixels with a dynamic of 16000 grey levels.

After windowing, the digitized frame images (2048 x 1400) are analysed by a crosscorrelation algorithm using the software PIVIS developed at the IMFT (Service Signaux et Images). The algorithm is based on a bi-dimensional FFT cross-correlation function implemented in an iterative scheme with a sub-pixel image deformation, according to Lecordier et al. [8]. Furthermore, the flow field was analysed by cross-correlating $50 \%$ overlapping windows to satisfy Nyquist's criterion. The images are subdivided into rectangular interrogation windows of size $16 \times 16$ pixels. By this way, the smallest window is $2.3 \times 2.3 \mathrm{~mm}$ in a whole field which size is $30 \times 30 \mathrm{~cm}$. Particular efforts were made to reach a sufficiently high resolution to be able to see the effects of the microjets near the leading edge. With all these settings, the correlation peaks are good enough and the need for interpolation is minimal after averaging on the 1000 vector fields.

\subsection{Airfoil model}

The two-dimensional ONERA D airfoil model (Figure 3) has the dimensions of $1 \mathrm{~m}$ span (L) and $0.35 \mathrm{~m}$ chord (C) and was manufactured with epoxy resin. The leading edge of the model consists of a $0.7 \mathrm{~m}$ wide removable hollow insert, making possible the installation 
of the control devices inside the airfoil. The model was mounted to the balance through the tunnel sidewalls by a spanwise-extended steel tube. A row of 41 streamwise pressure taps is located at midspan. The nominal orifice diameter of the pressure taps is $0.5 \mathrm{~mm}$. Seven 6-port pressure conditioners were connected to the pressure taps then, the signal delivered by the conditioners was transmitted to a 12-bit acquisition board to get the surface static pressure readings. Hot-wire measurements showed a $50 \mathrm{~mm}$ thick boundary layer thickness on the tunnel wall at the location where the airfoil was tested. Consequently, two side plates were installed on the model to prevent cross-flow. Experiments were conducted using the naturally occurring laminar boundary layer as well as for a turbulent boundary layer. The boundary layer is made turbulent by tripping it using a very thin carborundum strip (roughness diameter $0.3 \mathrm{~mm}$ ) deposited along a curvilinear coordinate $\mathrm{s} / \mathrm{C}=1 \%$ from the geometrical leading edge.

\subsection{Actuators design}

\subsubsection{The microjets}

The first actuator which has been experimented is the «microjets» actuator. It consists of (Figure 4 - right):

- 82 cylindrical micro holes regularly drilled every $5 \mathrm{~mm}$. Each hole has a diameter $0.4 \mathrm{~mm}$,

- two plenum chambers intended for obtaining uniform spanwise output velocities,

- flexible plumbing connecting the plenum chambers to the compressed air supply, outside the test section.

The micro holes were drilled at $\mathrm{s} / \mathrm{C}=2.8 \%$, perpendicularly to the chord. Because of design reasons, the micro holes cover $40 \%$ of the wing total span. There is a distance of 
$45 \mathrm{~mm}$ between the two holes located at midspan due to the presence of the pressure taps.

A blowing rate momentum $C_{\mu}$ is defined in Eq. (1) where $U_{*}$ is the incoming flow velocity, $\rho_{\infty}$ is air density, $\mathrm{Q}$ the flow rate injected through the holes, $\mathrm{V}_{\mathrm{j}}$ the exit velocity and $\mathrm{S}_{\mathrm{ref}}$ a reference surface defined by $\mathrm{S}_{\text {ref }}=\mathrm{L} \times \mathrm{C}=0.35 \mathrm{~m}^{2}$.

$$
C_{\mu}=\frac{Q V_{j}}{\frac{1}{2} \rho_{\infty} S_{r e f} U_{\infty}^{2}}
$$

Results of test bench experiments are gathered in Table 1, where the blowing rate momentum is calculated for an incoming velocity $\mathrm{U}_{\infty}=40 \mathrm{~m} / \mathrm{s}$.

\begin{tabular}{|c|c|c|c|c|}
\hline $\begin{array}{c}\text { Experiment } \\
\text { number }\end{array}$ & $\begin{array}{c}\text { Plenum chamber } \\
\text { pressure } \mathrm{P}_{\mathrm{C}}(\mathrm{bar})\end{array}$ & $\begin{array}{c}\text { Flow rate } \mathrm{Q} \\
(\mathrm{L} / \mathrm{min})\end{array}$ & $\begin{array}{c}\text { Exit velocity } \\
\mathrm{V}_{\mathrm{j}}(\mathrm{m} / \mathrm{s})\end{array}$ & $\mathrm{C}_{\mu}$ \\
\hline 1 & 1,29 & 132,50 & 205,00 & $0,198 \%$ \\
\hline 2 & 1,69 & 199,79 & 286,47 & $0,417 \%$ \\
\hline 3 & 2,11 & 251,52 & 313,16 & $0,574 \%$ \\
\hline 4 & 2,54 & 302,18 & 313,16 & $0,690 \%$ \\
\hline
\end{tabular}

Table 1. Characterization of the microjets actuator performance

\subsubsection{The tangential blowing actuator}

A thin metal plate is installed on the model in order to deviate a jet coming out from a slot perpendicular to the wall (Figure 4).

Consequently, the actuator involves the presence of a small step and a local deformation which has been softened applying modelling clay. The effects of these small discontinuities have been studied by turning off the actuator and by comparing the aerodynamic behaviour of the profile with the baseline model (without actuator). The 
tangential slot is located at $\mathrm{s} / \mathrm{C}=8 \%$. The device (Figure $4-$ left) is very similar to the microjets actuator and consists of:

- two tangential slots,

- two plenum chambers,

- $\quad$ flexible plumbing connecting each plenum chamber to the compressed air supply through two distributors.

The slots cover $56 \%$ of the wing total span. There is a distance of $48 \mathrm{~mm}$ between the two slots at midspan because of the presence of the pressure taps.

A characterization of the jet velocities exiting the slots is made through Pitot tube measurements. Obtained velocity profiles are plotted in Figure 5. The mean velocity is found to be approximately $60 \mathrm{~m} / \mathrm{s}$ on each slot, yet, the plots highlights a nonuniformity of the jets in the spanwise direction. No further improvement of the velocity profiles could have been achieved.

\section{Results}

\subsection{Baseline configuration}

Preliminary experiments mainly consist of surface flow visualizations using pigmented linseed oil, pressure and force measurements performed at various freestream velocities, in the range $30-60 \mathrm{~m} / \mathrm{s}$, which corresponds to Reynolds numbers varying between $0.7 \times 10^{6}$ and $1.4 \times 10^{6}$. For naturally occurring laminar boundary layer (Figure $6-$ left):

- The basic wing has a very docile stall at low Reynolds numbers $\left(\operatorname{Re}_{\mathrm{C}} \leq 0.93 \times 10^{6}\right)$. This type of stall mechanism, called «leading edge long bubble stall» is characterized by the gradual downstream movement of the separated flow region from the leading edge, as the angle of attack increases; 
- At higher Reynolds numbers $\left(\operatorname{Re}_{C} \geq 1.17 \times 10^{6}\right)$, the wing is characterized by flow separation taking place rather abruptly over the entire top surface of the airfoil when the bubble bursts, with the origin of this separation occurring close to the leading edge: it is called «leading edge short bubble stall».

For tripped boundary layer (see Figure 7 for details on boundary layer tripping), at every Reynolds numbers investigated, stall is very smooth (Figure $6-$ right) and $C_{\text {Lmax }}$ is decreased due to the presence of the carborundum strips. The corresponding stall angles are increased. Finding a satisfying roughness size to trip the boundary layer is difficult for two reasons: first, separation occurs nearby the leading edge so there is a short distance between the position of the roughness elements and the separation line (and consequently, the boundary layer thickness we are working with is very low); then, there is a negative/favourable pressure gradient which is very inconvenient to force transition. Nevertheless, carborundum is used because it allows dissociating the effects of control with the effects of transition.

The results of lift measurements are confirmed by on-surface flow visualizations (Figure 8 \& 9). Note that flow is coming from the bottom to the top on these figures. Although, this method highlights a spanwise asymmetry of the flow (it is supposed that this dissymmetry is due to the presence of the wall and to the aspect ratio), oil film visualizations also reveal that separation is smoother using the carborundum strips than with the naturally occurring laminar boundary layer. Surface static pressure distributions (Figure 10) are in good agreement with the previous observations. It can be seen that the magnitude of the suction peak increases as the angle of attack is increased, up to an angle of $\alpha=11^{\circ}$. With reference to these data, characterizing the presence of a localized separation bubble is difficult because there is an insufficient number of pressure ports on the model to reveal any flat pressure distribution. The bubble may be highlighted using the oil film method though. It is 
interesting to note that with one degree change, the suction peak, for the naturally occurring laminar boundary layer case, has decreased drastically, suggesting a stall which is more violent than for the wing with a tripped boundary layer.

\subsection{Effects of TBA}

Although the principle of this actuator is well-know in aerodynamics, the goal of these experiments is to check the possibility for controlling separation on such a profile. Force measurements for the baseline configuration are made on a wing equipped with a disabled actuator in order to quantify the modifications in aerodynamic forces due to the profile alteration resulting from the presence of the actuator; this is made for both laminar and tripped boundary layer.

For the naturally occurring laminar boundary layer (Figure 11), stall is quite abrupt, indicating that the separation point may be positioned by the geometrical singularity. Applying a $60 \mathrm{~m} / \mathrm{s}$ tangential blowing causes an increase in the value of $\mathrm{C}_{\mathrm{Lmax}}$. The angle of attack for which stall occurs is increased from 11 degrees for the baseline wing to 13 degrees for the case of TBA actuation. Before stall incidence, the use of TBA does not seem to have any significant effect over the drag coefficient. The decrease in drag at angles of attack between 11 and 15 degrees is due to the suppression of the separated region over the wing. For higher angles of attack $\left(\alpha \geq 15^{\circ}\right)$, TBA produces a drag increase. Remember that these force measurements are made while control is applied on $56 \%$ of the wing span: balance measurements only provide information of the global effects over the wing of a local actuation.

For the tripped boundary layer (Figure 12), the wing still has a docile stall. Applying TBA actuation generates an increase of the $C_{L}$ value when the stall angle of attack is reached. A drag decrease is observed for the same range of angles of attack as for actuation on a 
naturally occurring laminar boundary layer. Actuation causes an increase in the value of $\mathrm{C}_{\mathrm{L}}$ after the stall but the gain is less as compared to Figure 11. Flow visualizations (Figure 13) indicate that a reattachment (red arrows) is induced by actuation in the region where blowing is applied; yet, a separated region is still present near the centreline (blue arrows).

\subsection{Effects of microjets}

Force measurements for the baseline configuration are made on a wing equipped with a disabled actuator in order to quantify the modifications in aerodynamic forces due to the presence of the holes; this is made for both laminar and tripped boundary layer.

For the naturally occurring laminar boundary layer (Figure 14), stall is still quite abrupt. Applying microjets control does not increase the value of $\mathrm{C}_{\mathrm{Lmax}}$. Moreover, the angle of attack for which stall occurs is not increased. Yet, microjets actuation maintains the level of the lift coefficient after the stall angle: the gain in $\mathrm{C}_{\mathrm{L}}$ is about $30 \%$ compared to the baseline configuration. Before stall incidence, the use of microjets does not seem to have any significant effect over the drag coefficient. The decrease in drag at angles of attack between 12 and 16 degrees is due to the suppression of the separated region over the wing, as suggested by the wall flow visualizations (Figure 16). For higher angles of attack $(\alpha \geq$ $15^{\circ}$ ), microjets produce a drag increase. Remember that these force measurements are made while control is applied on $40 \%$ of the wing span. PIV results are in good agreement with these observations. The longitudinal component of the mean velocity field around the wing at an angle of attack of 16 degrees and a Reynolds number of $4.67 \times 10^{5}$ is represented in Figure 18. The shape of the airfoil is plotted on the graphs and the shadow zone represented in black is a roughly $5 \mathrm{~mm}$ non-measured zone near the wall. The velocity fields presented here are obtained by averaging 100 vector fields (because of article deadline reasons). For the case of no actuation, the deep blue area representing the negative 
velocities in the separated boundary layer indicates that the wake of the wing is very large. On the other hand, for the actuated case, areas of negative velocities have totally disappeared and even there is still a region of low momentum (green areas) near the wall, the flow seems attached over the leading edge. This result confirms not only the microjets efficiency observed by wall visualization up to angles of attack of 14 degrees but for higher angles (here 16 degrees) at least for a Reynolds number of $4.7 \times 10^{5}$.

For the tripped boundary layer (Figure 15), the wing still has a docile stall. Applying microjets control generates an increase of the $C_{L}$ value for angles of attack higher than the stall angle. A drag decrease is observed for angles of attack higher than 11 degrees. Actuation causes a sensible increase in the value of $\mathrm{C}_{\mathrm{L}}$ after the stall but the gain is less important than previously (Figure 14). The separated region over the wing disappears when control is applied, as suggested by the wall flow visualizations (Figure 17). The comparison between Figure 14 and Figure 15 leads us to the conclusion that the effects of the microjets on the boundary layer transition are not negligible; yet, the device seems to be able to control flow separation since the effects on performances is still visible for the tripped boundary layer.

\section{Conclusions}

This study presents the development of two fluidic actuators - namely, microjets and tangential blowing actuator (TBA), and demonstrates their effects in the control of flow separation control on an ONERA D profile. Most of the tests were performed at freestream velocities between $20 \mathrm{~m} / \mathrm{s}$ (for PIV) and $40 \mathrm{~m} / \mathrm{s}$, corresponding to Reynolds numbers in the range $0.47 \times 10^{6}-0.93 \times 10^{6}$. The angle of attack was varied from -2 to 20 degrees. Experiments were conducted using the naturally occurring laminar boundary layer as well as for a turbulent boundary layer. In such a case, rough strips were used in the vicinity of 
the leading-edge. Results show that both actuators are more efficient in the case of naturally occurring laminar boundary layer: a maximum of $30 \%$ gain in $\mathrm{C}_{\mathrm{L}}$ has been reached using the microjets. A drag decreases is observed for angles of attack in the range 11 - 15 degrees. On-surface visualizations and PIV suggest that the separated region is eliminated by the control. Applying actuation on a tripped boundary layer has to a lesser extent, the same effects: the gain in $\mathrm{C}_{\mathrm{L}}$ is less important but still observable. Future works will deal with a new model based on a NACA 0015 profile and characterized by trailingedge appearing separation. The goal of this study will be to validate the efficiency of these two actuators and to implement new devices based on instationnary excitation (synthetic and pulsed jets). We are also planning more detailed studies with the goal of examining the important parameters that determine the efficiency of control and understanding some of the fundamental mechanisms behind these control techniques.

\section{References}

P.R. Ashill, J.L. Fulker, K.C. Hackett, Research at Dera on Sub Boundary Layer Vortex Generators (SBVGs), AIAA Paper 2001-0887.

P.R. Ashill, J.L. Fulker and K.C Hackett, Studies of flows induced by Sub Boundary Layer Vortex Generators (SBVGs), AIAA Paper 2002-0968.

A. Darabi and I. Wygnanski, Active management of naturally separated flow over a solid surface. Part.1. The forced reattachment process, J. Flui Mech., vol. 510, pp105-129, 2004.

A. Darabi and I. Wygnanski, Active management of naturally separated flow over a solid surface. Part.2. The separation process, J. Flui Mech., vol. 510, pp131-144, 2004.

A. Seifert, S. Eliahu, D. Greenblatt and I. Wygnanski, Use of Piezoelectric Actuators for Airfoil Separation Control, AIAA J., vol. 36, pp. 1535-1537, 1998.

V. Kumar and F.S. Alvi, Use of Supersonic Micro jets for Active Separation Control in Diffusers, AIAA Paper 2003-4160. 
P. R. Viswanath and K.T. Madhavan, Control of Trailing-Edge separation by tangential blowing inside bubble: a novel approach, AIAA Paper 2003-0223.

B. Lecordier, D. Demare, L.M.J. Vervisch, J. Réveillon and M. Trinité, Estimation of the accuracy of PIV treatments for turbulent flow studies by direct numerical simulation of multi-phase flow, Meas. Sci. Technol. 12 No 9, pp. 1382-1391, September 2001.

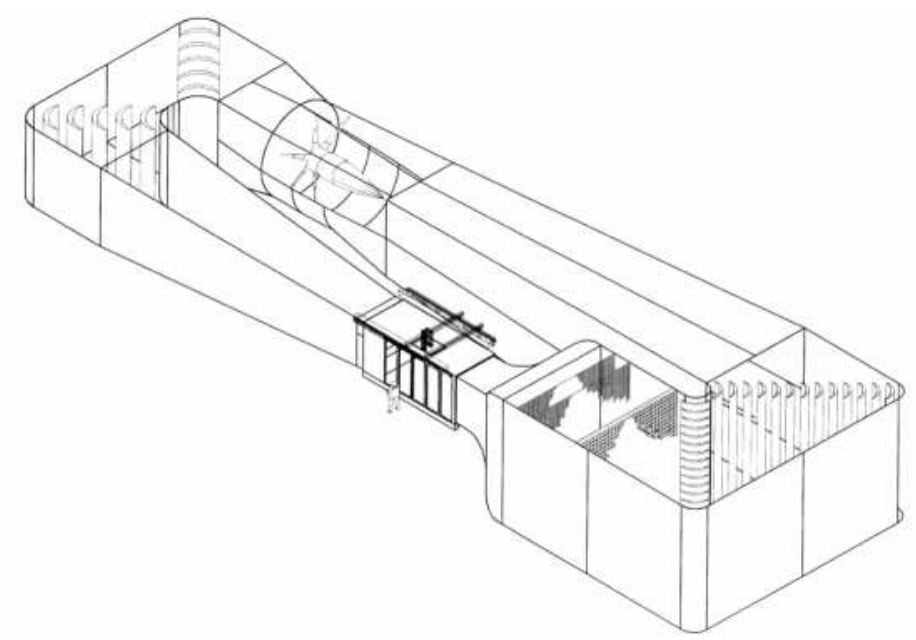

Figure 1. The «Béton» wind-tunnel at LEA

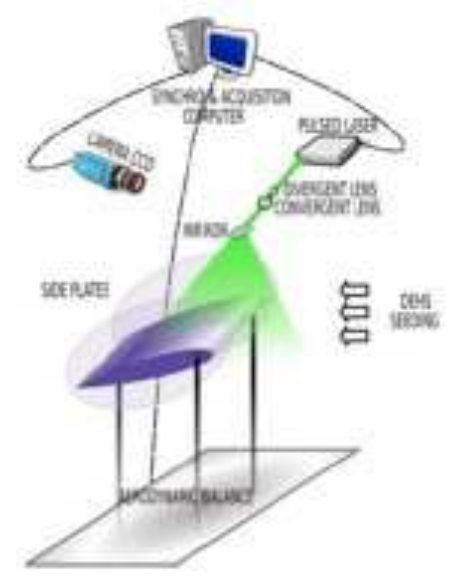

Figure 2. Experimental PIV set up at IMFT 



Figure 3. The ONERA D airfoil model
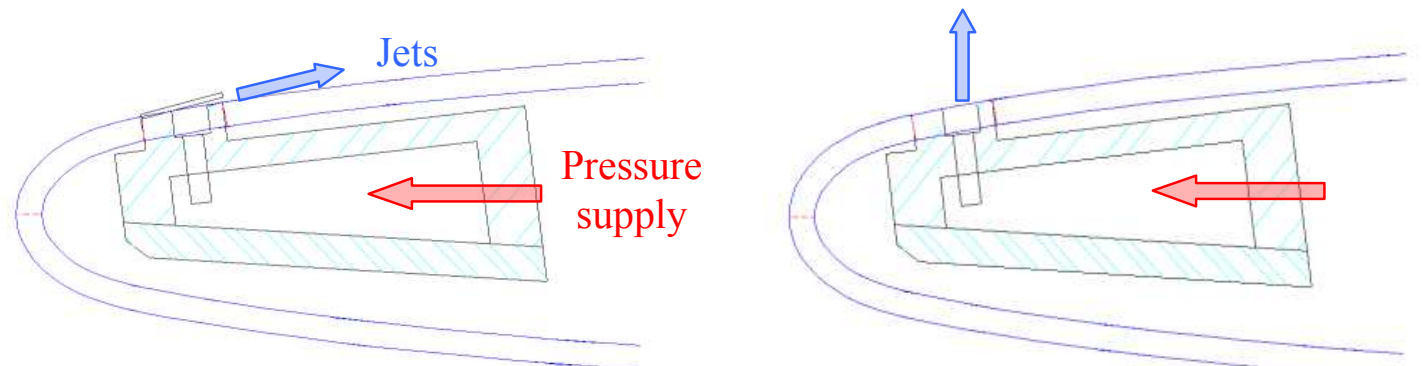

Figure 4. TBA (left) and microjets (right) principle schemes.

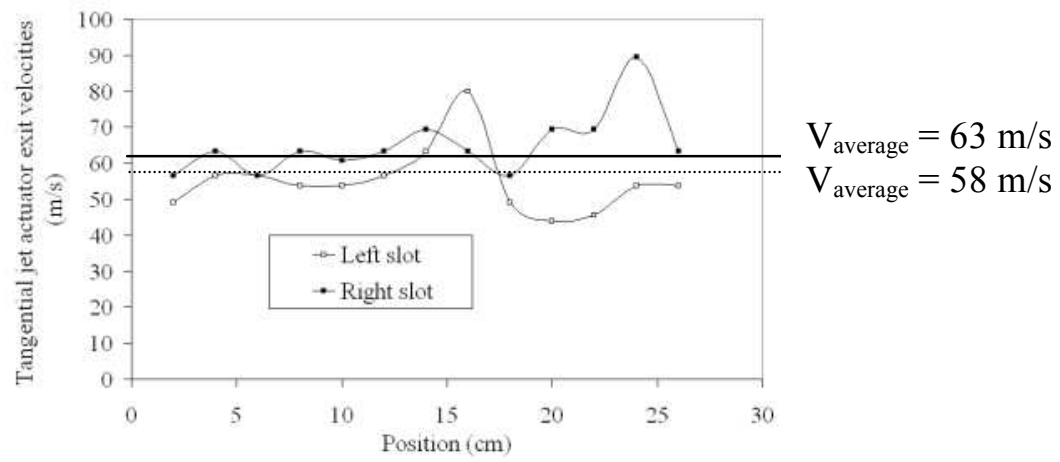

Figure 5. Velocity profiles at the exits of the slots. 

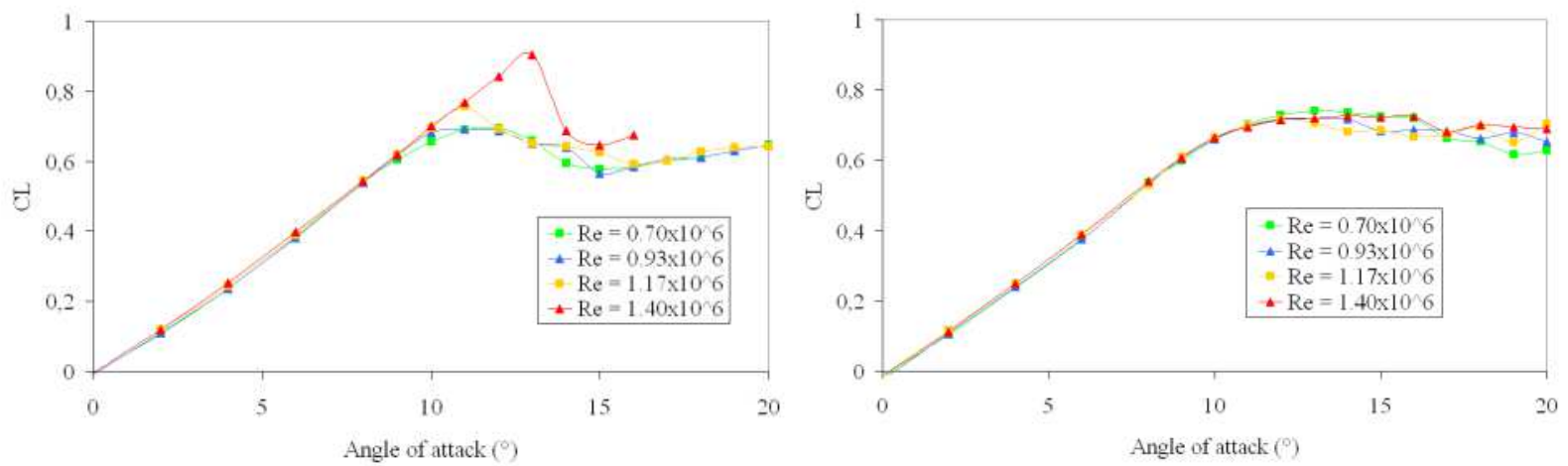

Figure 6. Lift coefficient (CL) vs. Angle of attack for the baseline wing: naturally occurring laminar boundary layer (left), tripped boundary layer (right).

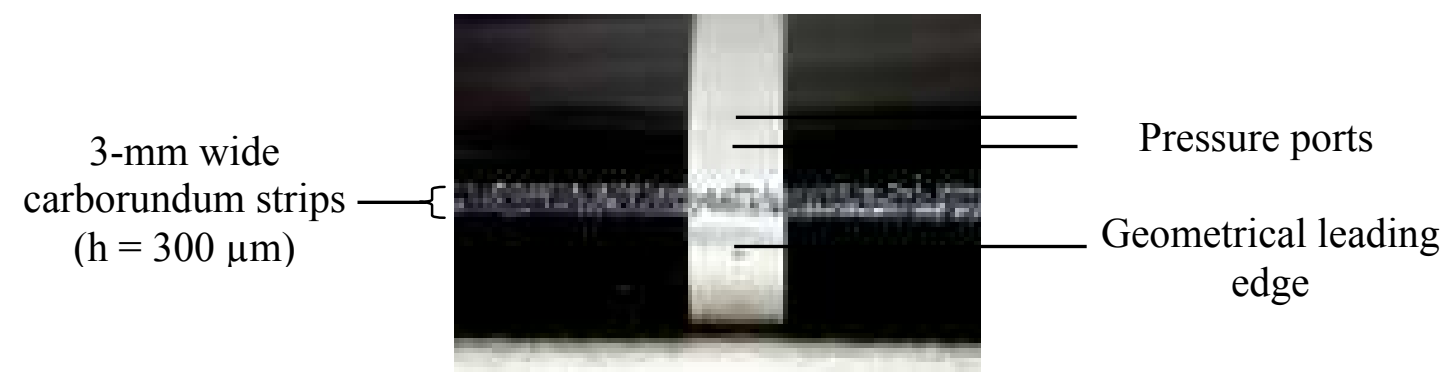

Figure 7. Detailed view of the roughness trip used for forcing boundary layer transition.

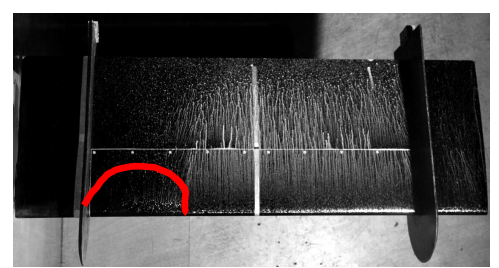

$\alpha=10^{\circ}$

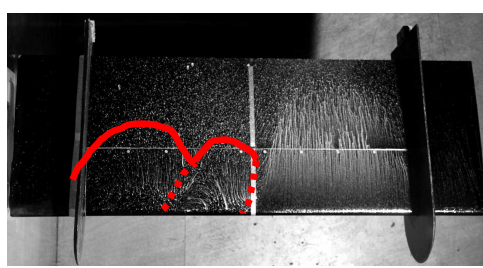

$\alpha=11^{\circ}$

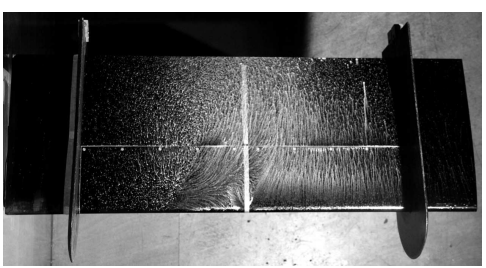

$\alpha=12^{\circ}$

Figure 8. Surface flow visualizations of the baseline wing at $\operatorname{Re}_{C}=0.93 \times 10^{6}$ (naturally

occurring laminar boundary layer). Flow is completely separated at $\alpha=12^{\circ}$.

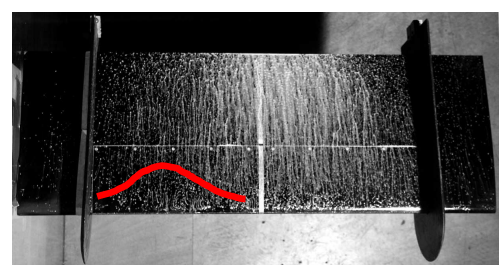

$\alpha=10^{\circ}$

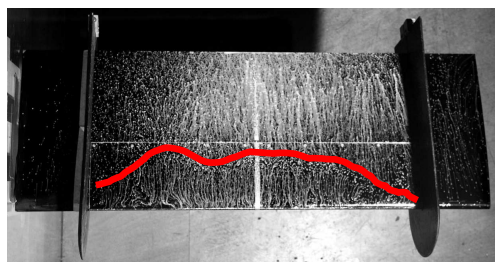

$\alpha=12^{\circ}$

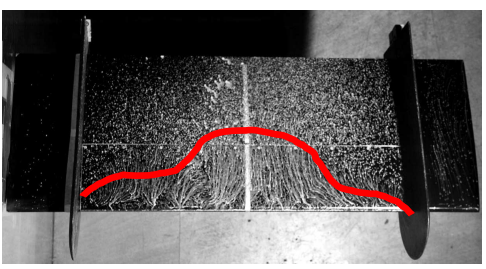

$\alpha=14^{\circ}$

Figure 9. Surface flow visualizations of the baseline wing at $\operatorname{Re}_{C}=0.93 \times 10^{6}$

(tripped boundary layer). 

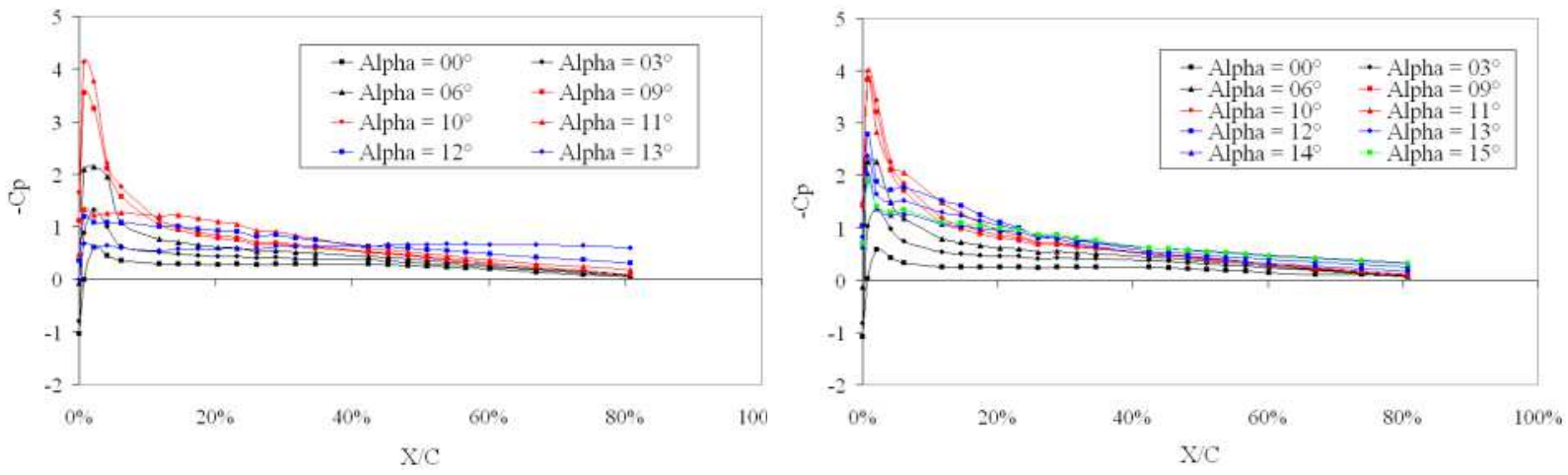

Figure 10. Surface static pressure distribution of text wing at $\operatorname{Re}_{C}=0.93 \times 10^{6}$ : naturally occurring laminar boundary layer (left), tripped boundary layer (right)
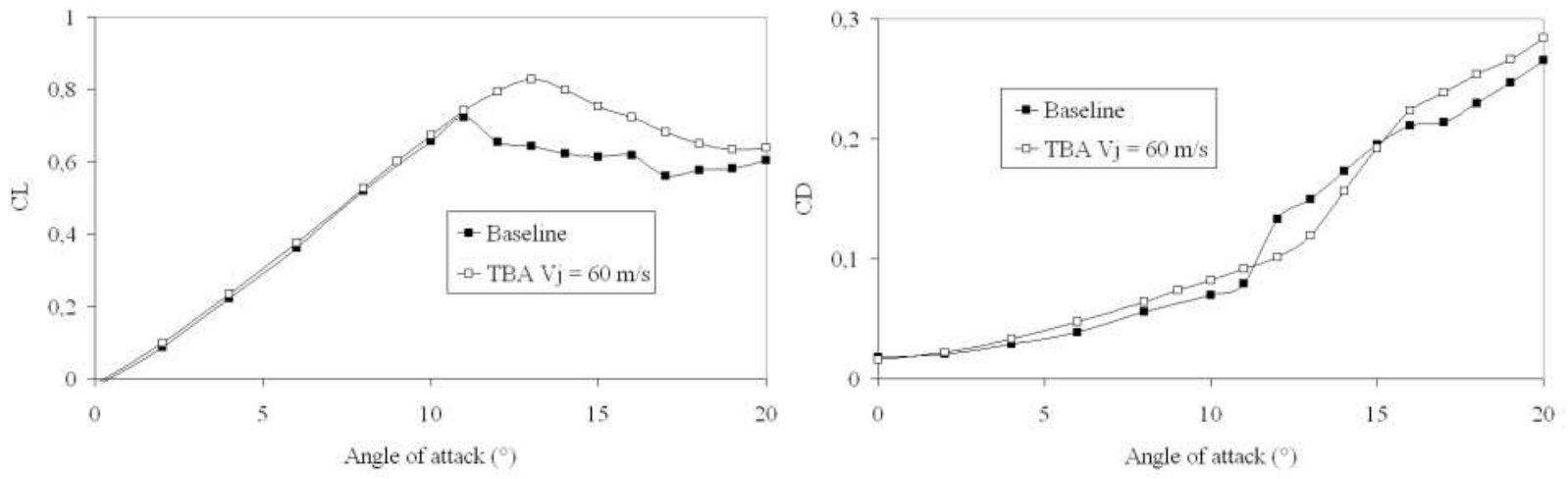

Figure 11. Effect of TBA on aerodynamic performance of the wing at $\operatorname{Re}_{C}=0.93 \times 10^{6}$ :

naturally occurring laminar boundary layer. Lift coefficient (CL) and drag coefficient (CD) vs. angle of attack ( $\alpha)$
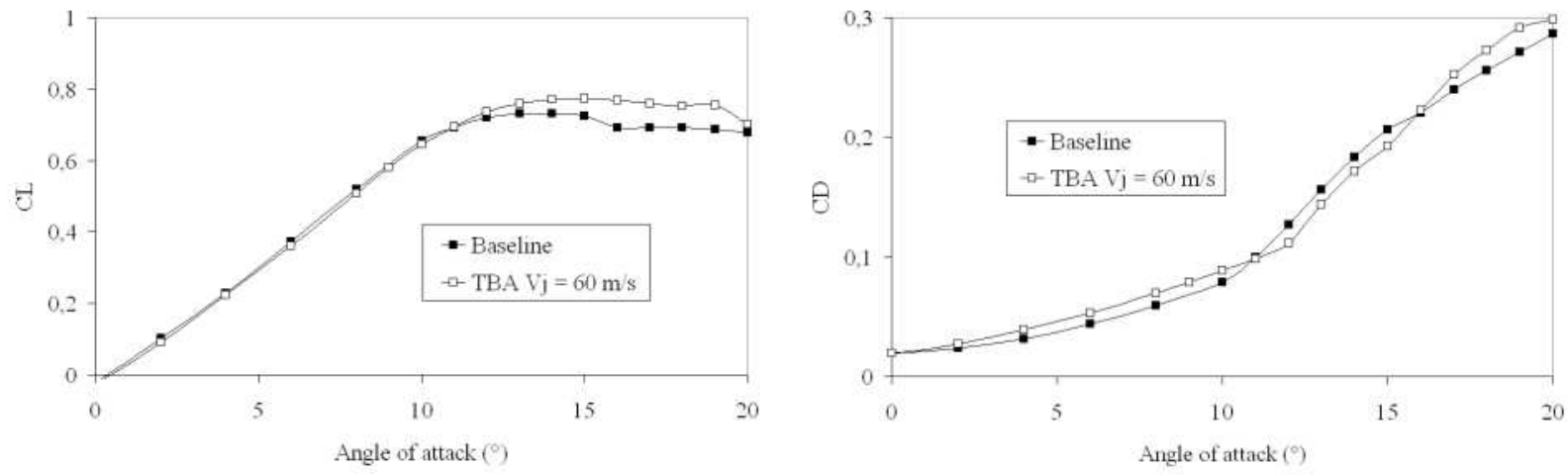

Figure 12. Effect of TBA on aerodynamic performance of the wing at $\operatorname{Re}_{\mathrm{C}}=0.93 \times 10^{6}$ : tripped boundary layer. Lift coefficient (CL) and drag coefficient (CD) vs. angle of attack 




Figure 13. Surface flow visualizations of the wing with TBA actuation at $\operatorname{Re}_{\mathrm{C}}=0.93 \times 10^{6}$ (tripped boundary layer). Angle of attack is set to 12 degrees.
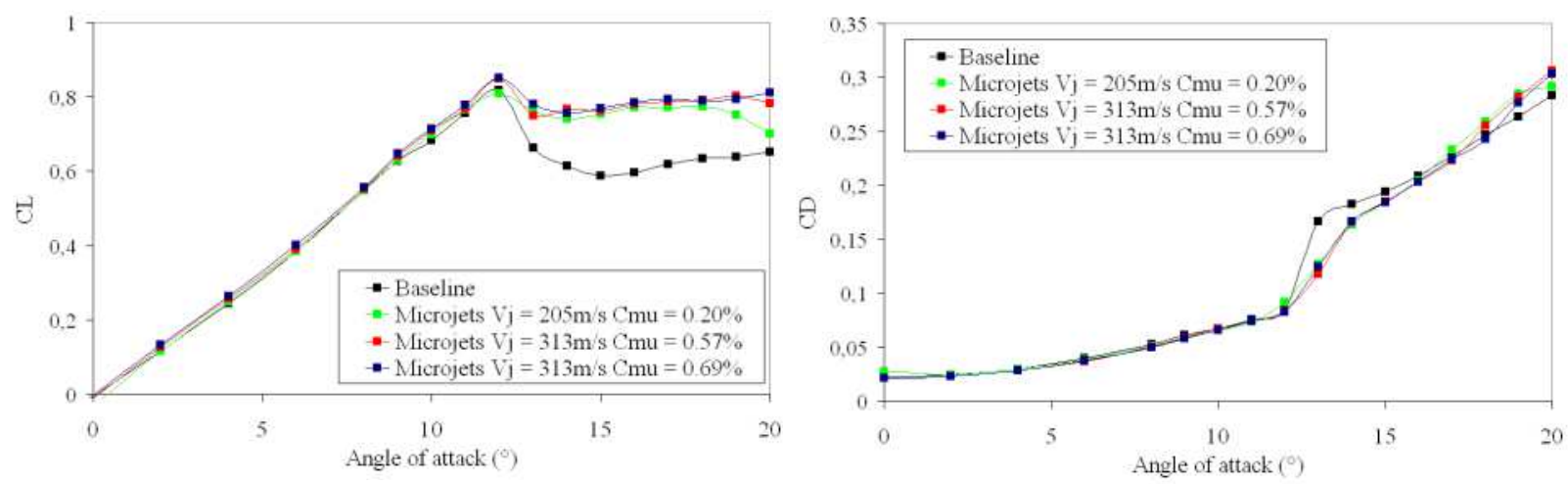

Figure 14. Effect of microjets on aerodynamic performance of the wing at $\operatorname{Re}_{C}=0.93 \times 10^{6}$ : naturally occurring laminar boundary layer. Lift coefficient (CL) and drag coefficient (CD) vs. angle of attack $(\alpha)$
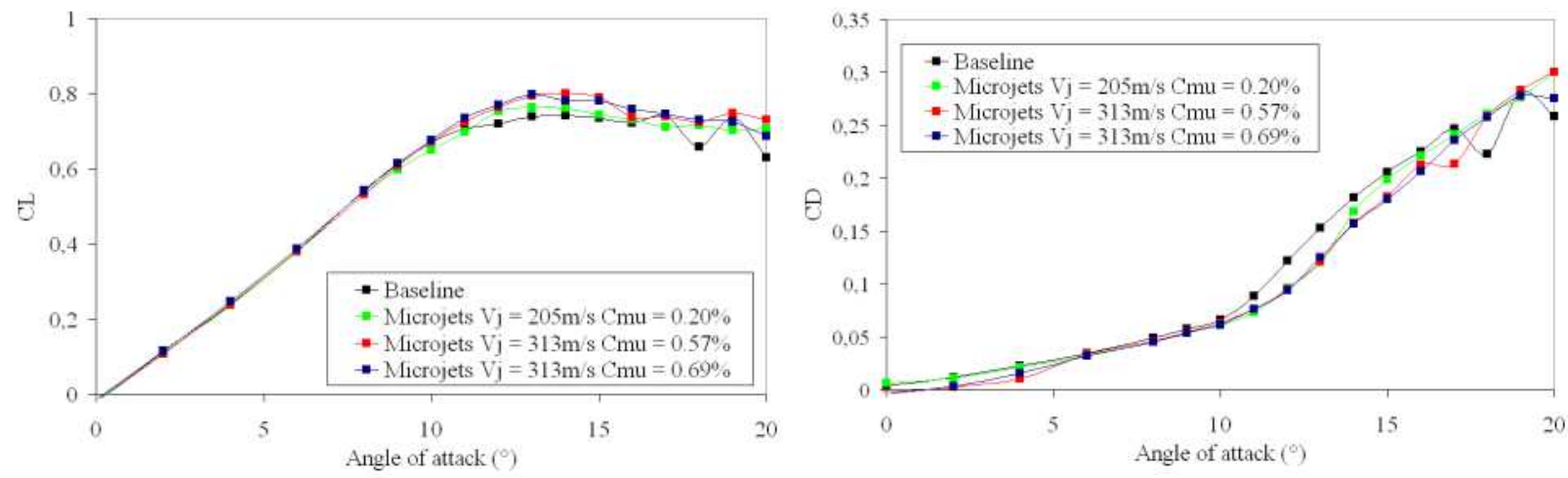

Figure 15. Effect of microjets on aerodynamic performance of the wing at $\operatorname{Re}_{C}=0.93 \times 10^{6}$ : tripped boundary layer. Lift coefficient (CL) and drag coefficient (CD) vs. angle of attack 

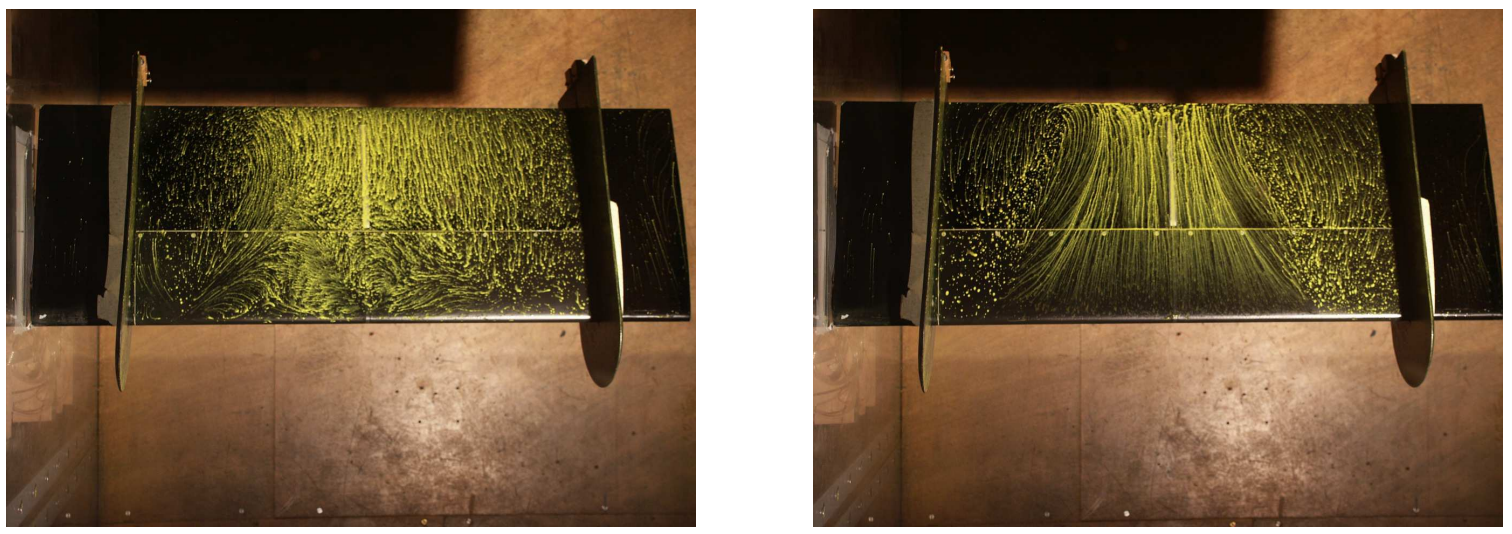

Figure 16. Surface flow visualizations of the wing with microjets actuation at $\operatorname{Re}_{C}=$ $0.93 \times 10^{6}$ (naturally occurring laminar
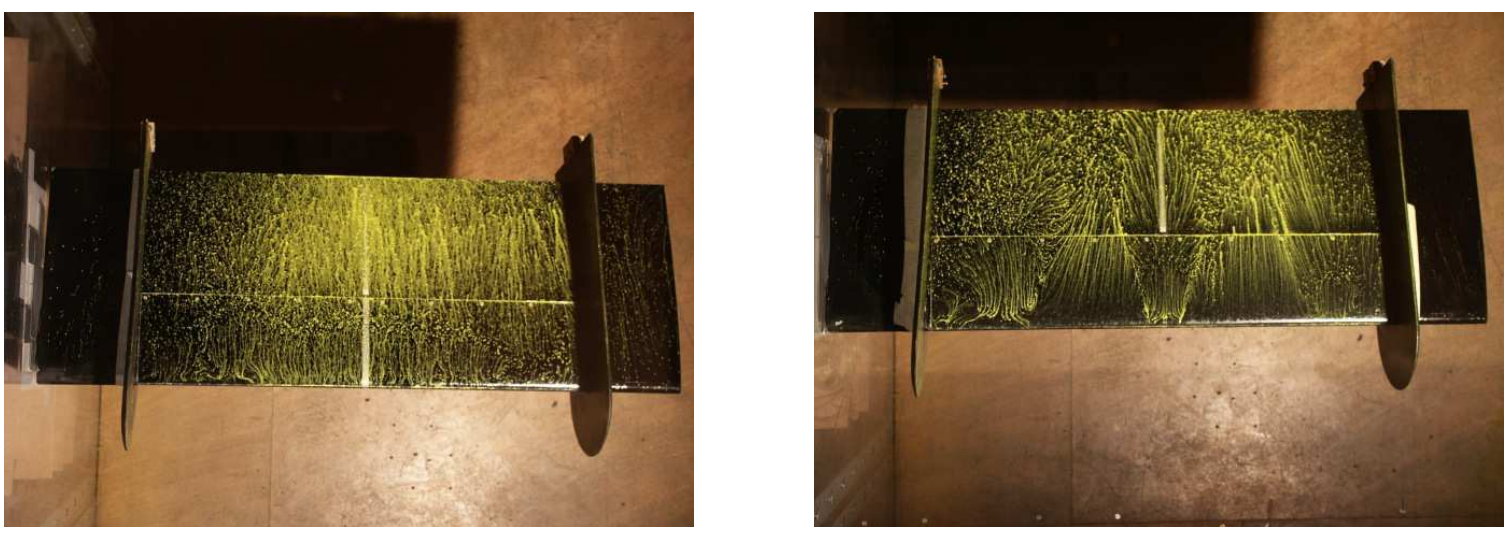

boundary layer). Angle of attack is set to 14

degrees.

Figure 17. Surface flow visualizations of the wing with microjets actuation at $\operatorname{Re}_{C}=$ $0.93 \times 10^{6}$ (tripped boundary layer). Angle of attack is set to 12 degrees.

u $\quad 0=15^{*}+R_{\mathrm{e}}=4570+65$ Contoi aff

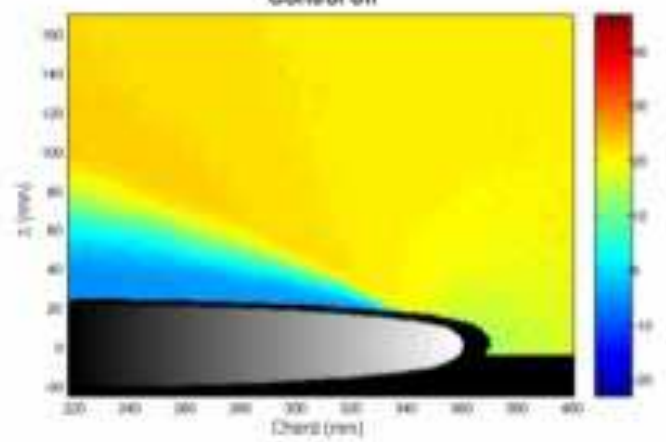

$4 \quad \alpha=18 *-F_{e}=487 e+05$

Centreian

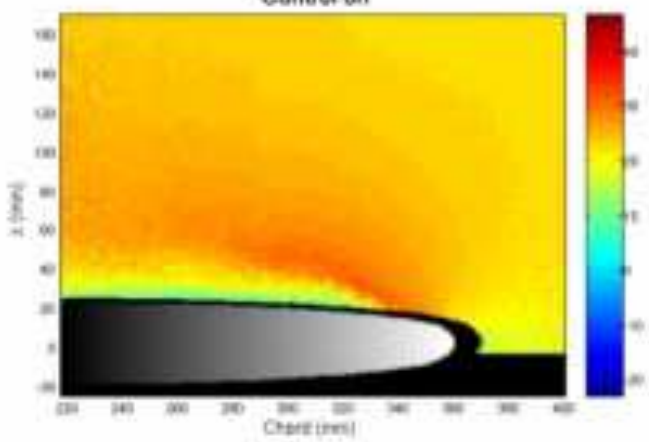


Figure 18. Mean velocity field over the wing at $\operatorname{Re}_{C}=0.93 \times 10^{6}$ : baseline (left) and activation of the microjets (right). Naturally occurring transition. Angle of attack is set to 16 degrees. 